BORGES, E. F.; et al. Educação Fiscal, Terceiro Setor e Funções de Governo...

\title{
Educação Fiscal, Terceiro Setor e Funções De Governo: Uma Análise da Influência do Programa de Educação Fiscal do RN nos Indicadores das Funções de Governo dos Municípios ${ }^{1}$
}

\section{Education Fiscal Third Sector and Functions Of Government: An Analysis of the Influence of Education Program in Fiscal Indicators of the RN functions Government of Municipalities}

\author{
Erivan Ferreira Borges \\ Doutor em Ciências Contábeis. Professor Adjunto do Departamento de Ciências Contábeis da UFRN. \\ Endereço: Universidade Federal do Rio Grande do Norte, Centro de Ciências Sociais Aplicadas. \\ Campus Universitário Lagoa Nova, CEP: 59078-970 - Natal, RN - Brasil - Caixa-postal: 1524 \\ Telefone: (84) 3215-3486, e-mail: erivanferreiraborges@yahoo.com.br \\ José Matias-Pereira \\ Professor Doutor da Universidade de Brasília. \\ Programa de Pós-Graduação em Ciências Contábeis UnB/UFPB/UFRN \\ Endereço: Universidade de Brasília, FACE, Campus da UnB, ICC Norte, Edifício da FACE \\ CEP: 70910970 - Brasília, DF - Brasil. \\ Telefone: (61) 3307-0807, e-mail: matias@unb.br \\ Gilmara Mendes da Costa Borges \\ Professora Assistente do Departamento de Ciências Contábeis da UFRN. \\ Doutoranda em Ciências Contábeis UnB/UFPB/UFRN \\ Endereço: Universidade Federal do Rio Grande do Norte, Centro de Ciências Sociais Aplicadas. \\ Campus Universitário, Lagoa Nova, CEP: 59.078-970 - Natal, RN - Brasil \\ Telefone: (84) 3215-3486, e-mail: borgesgilmara@yahoo.com.br \\ José Jailson da Silva \\ Professor Assistente do Curso de Ciências Contábeis da UFRN \\ Endereço: Universidade Federal do Rio Grande do Norte, Centro de Ciências Sociais Aplicadas. \\ Av. Capitão Moura Gouveia, Lagoa Nova, CEP: 59.080-000 - Natal, RN - Brasil. \\ Telefone: (84) 3215-3486, e-mail: professorjailsonufrn@yahoo.com.br
}

\section{RESUMO}

Este artigo apresenta uma análise do impacto causado nos indicadores sociais de funções de governo dos municípios sedes das entidades de terceiros setor beneficiárias dos repasses do Programa de Educação Fiscal do RN (PEF/RN) entre os exercícios 2004 e 2009. O PEF/RN tem como objetivos

\footnotetext{
${ }^{1}$ Artigo recebido em 01.06.2013. Revisado pelos pares em 23.10.2013 (blind review). Ajustado e Aceito para publicação em 16.10.2013. Recomendado para publicação por José Ribamar Marques de Carvalho (Editor Científico). Publicado em 12.12.2013. Organização responsável UACC/CCJS/UFCG.
}

REUNIR - Revista de Administração, Contabilidade e Sustentabilidade ISSN: 2237-3667 - Vol.3, no 4, Set./Dez., p. 39-61, 2013. 


\section{BORGES, E. F.; et al. Educação Fiscal, Terceiro Setor e Funções de Governo...}

promover e institucionalizar a educação fiscal para o pleno exercício da cidadania, sensibilizar o cidadão para a função socioeconômica do tributo, proporcionar-lhes conhecimentos sobre administração pública, e incentivar o acompanhamento pela sociedade da aplicação dos recursos públicos (PNEF MF/MEC, 2002; PEF/RN, 1997). A pesquisa buscou verificar se a atuação dessas entidades, a partir do recebimento de recursos advindos do PEF, impacta significativa e positivamente nos indicadores sociais dos seus municípios de domicílios. Utilizando-se o teste de hipóteses para médias emparelhadas, os resultados indicam que de maneira geral houve variação positiva nos indicadores, com reflexo direto sobre as funções de assistência social, saúde, desporto e lazer. Quando segregada em estratos, os resultados indicam que esse impacto é concentrado nos municípios com populações superiores a 50.000 habitantes, resultado da concentração econômica na capital e região metropolitana. Como proposta de estudos posteriores, pode-se procurar entender quais são as principais dificuldades enfrentadas por tais entidades para captação dos recursos distribuídos pelo programa, desde aos aspectos cadastrais, acesso a informações e entidades comerciais parceiras. Também se recomenda verificar e investigar a efetividade na aplicação dos gastos, o impacto do programa na formação educacional da população e o que pensam os cidadãos dos municípios sedes sobre a atuação das entidades.

Palavras-chaves: Educação Fiscal. Terceiro setor. Indicadores sociais.

\section{ABSTRACT}

This paper presents an analysis of the impact on social indicators of governance functions of the municipalities in the third sector entities in receipt of transfers from the Education Program Fiscal RN (PEF / RN) between 2004 and 2009. PEF / RN aims to promote and institutionalize the education tax for the full exercise of citizenship, to sensitize the public to the socioeconomic function of the tax, giving them knowledge on public administration, and encourage monitoring by the company's use of public resources ( PNEFA MF / MEC, 2002; PEF / RN, 1997). The research sought to determine whether performance of these entities, the receipt of funds from the PEF, significant and positive impact on social indicators of their municipalities households. Using the hypothesis test for paired means, the results indicate that in general there was positive change in the indicators with a direct reflection on the functions of social welfare, health, sport and leisure. When secreted into strata, the results indicate that this impact is concentrated in cities with populations over 50,000, a result of economic concentration in the capital and metropolitan region. As a proposal for further studies, we can try to understand what are the main challenges faced by those entities to raise funds distributed by the program, since the registration points, access to information and business entities partner. It is also advisable to check and investigate the effectiveness of spending in the application, the program's impact on the educational background of the population and what they think the citizens of the municipalities in on the performance of entities.

Keywords: Tax Education. Third sector. Social indicators.

\section{INTRODUÇÃO}

Os modelos de gestão pública contemporânea exigem um Estado menos burocrático, mais flexível e eficiente, e voltado ao atendimento do cidadão (BRASIL, 2009; SILVEIRA e SILVEIRA, 2006; SLOMSKI, 2008; MATIAS-PEREIRA, 2009).

REUNIR - Revista de Administração, Contabilidade e Sustentabilidade ISSN: 2237-3667 - Vol.3, no 4, Set./Dez., p. 39-61, 2013. 


\section{BORGES, E. F.; et al. Educação Fiscal, Terceiro Setor e Funções de Governo...}

A orientação para resultados é uma fixação do novo paradigma da gestão pública, ou seja, o que está em foco são as novas formas de geração de resultados em um contexto contemporâneo complexo e diversificado (BRASIL PRODUTO 4, 2009). É dever do estado (e seus gestores) não só prestar contas dos recursos que administra, mas responsabilizar-se por seus atos e dotar o cidadão de conhecimentos e ferramentas que lhes permitam fiscalizá-lo.

Nesse contexto, a educação fiscal se apresenta como um processo necessário, pois uma das esferas mais negligenciadas pela sociedade é a do conhecimento, significado econômico, financeiro e social do tributo, principal fonte de receita pública. Esta temática tem sido uma preocupação para o Estado, caracterizada nas suas ações através da implantação de políticas públicas e na tentativa de promover a conscientização do cidadão, e permitir que este reflita sobre o seu real papel na ligação estado-cidadão.

Essa política nacional, devido a sua importância como um programa de consciência tributária para despertar a prática da cidadania começa a tomar força entre os estados da federação a partir de setembro de 1996, quando em reunião do Conselho Nacional de Política Fazendária - CONFAZ discute-se a implantação de um programa nacional permanente de conscientização tributária, passando a fazer parte da agenda, e culminando com um Convênio de Cooperação Técnica entre União, Estados e Distrito Federal.

O Programa Nacional de Educação Fiscal - PNEF foi desenvolvido pelo governo federal para promover e institucionalizar a Educação Fiscal para o pleno exercício da cidadania, uma vez que para seus articuladores “[...] é um trabalho de sensibilização da sociedade para a função socioeconômica do tributo"1. O PNEF originou-se em 1996 quando foi lançado o programa de conscientização tributária para despertar a prática da cidadania. Posteriormente, em 1999, tornou-se o Programa Nacional de Educação Fiscal - PNEF, e em 2002 foi finalmente regulamentado como Programa Nacional de Educação Fiscal - PNEF, através da Portaria Interministerial do Ministério da Fazenda (MF) e Ministério da Educação e Cultura (MEC) no. 413/02 de 31 de dezembro de 2002. O PNEF está sendo disseminado em todo o país sob a coordenação da Escola de Administração Fazendária - ESAF, Ministério da Fazenda e Ministério da Educação.

No Rio Grande do Norte o Programa de Educação Fiscal - PEF 2, foi instituído pelo Decreto no 13.621, de 05 de novembro de 1997. O PEF tem como objetivo despertar na população a consciência do que é cidadania e, assim, como reflexo, transmitir-lhe conhecimentos para torná-la apta a fiscalizar a correta aplicação dos recursos públicos, harmonizando a relação Estado/Cidadão, combatendo a sonegação e sensibilizando a população quanto à função sócio-econômica dos tributos.

REUNIR - Revista de Administração, Contabilidade e Sustentabilidade ISSN: 2237-3667 - Vol.3, no 4, Set./Dez., p. 39-61, 2013. 
BORGES, E. F.; et al. Educação Fiscal, Terceiro Setor e Funções de Governo...

Dados da Secretaria Estadual de Tributação indicam que através da Campanha Cidadão Nota $10^{3}$, a Secretaria de Estado da Tributação (SET) conseguiu arrecadar mais de 55.000.000,00 (cinqüenta e cinco milhões) de notas e cupons fiscais até março/2010. Segundo a atual direção do programa isso é extremamente positivo para o Estado, além de facilitar o trabalho feito pelos auditores fiscais em combater a sonegação fiscal.

Como se vê, frente a todas as características e objetivos sociais do PEF/RN, existe uma representatividade econômico-financeira subjacente ao alcance destes objetivos, que por sua vez motiva a elaboração deste estudo.

Diante do exposto anteriormente, tem-se o seguinte problema de pesquisa: Os repasses decorrentes do Programa de Educação Fiscal do RN (PEF/RN) às entidades do terceiro setor influenciam positivamente os indicadores das funções de governo dos municípios domicílios das entidades alcançados pelo programa? Por esse problema, a pesquisa objetiva demonstrar quais são as relações resultantes entre o $\mathrm{PEF} / \mathrm{RN}$ e o desempenho púbico, quanto a possível influência nos indicadores locais das funções de governo, a partir do recebimento de repasses pelas entidades do Terceiro Setor de cada município pesquisado.

\section{ASPECTOS TEÓRICOS RELEVANTES}

Como fundamento ao trabalho apresenta-se algumas discussões sobre o Programa de Educação Fiscal do RN e a relação entre Estado, o mercado e as organizações do terceiro setor beneficiadas com os repasses dos recursos.

\subsection{Educação Fiscal}

A educação fiscal é uma nova prática pedagógica que tem por objetivo conscientizar o cidadão sobre o significado sócio-econômico do tributo (ESAF, 2004). Como programa de governo, vem, enfrentando dificuldades de penetração nos mais diversos setores, especialmente no contexto acadêmico, sendo este um dos motivadores para a elaboração do presente artigo.

Conforme Grzybovski e Hahn (2006) ainda se vive no Brasil um estado de profundo desconhecimento das bases da sociedade em relação às coisas mais elementares, agravado, no caso do tributo, pela sua natureza impositiva. Para as autoras, ainda se confunde Estado com governo, contribuinte de direito com contribuinte de fato, governo com funcionário público e não se tem claro que o criador do Estado e, portanto, dos seus tributos, é o próprio povo. Esse cenário evidencia a importância de programas, tanto de iniciativa privada quanto pública, 
BORGES, E. F.; et al. Educação Fiscal, Terceiro Setor e Funções de Governo...

que tenham por fim desenvolver a consciência fiscal no cidadão brasileiro (GRZYBOVSKI; HAHN, 2006, p. 851).

Pertuzatti e Merlo (2005) desenvolveram um trabalho específico sobre o Programa de Educação Fiscal do Estado de Santa Catarina, no qual propõem uma reflexão sobre o público atingido, além de investigar qual a importância do profissional contábil no processo. No trabalho analisam o progresso obtido pela sociedade, referenciando a participação do Estado como mediador da igualdade entre as pessoas, e destacam nesse contexto, o problema da divisão igualitária de recursos, como processo da intervenção desse estado, e de atores sociais como o profissional contábil.

De certa forma, o trabalho também busca esse entendimento do impacto do programa na sociedade, relacionando os repasses proporcionados pelo programa $\mathrm{PEF} / \mathrm{RN}$ nos indicadores sociais dos municípios.

\subsection{Programa de Educação Fiscal do RN (PEF-RN)}

O Programa de Educação Fiscal do RN (PEF/RN) tem como objetivos promover e institucionalizar a educação fiscal para o pleno exercício da cidadania, sensibilizar o cidadão para a função socioeconômica do tributo, proporcionar-lhes conhecimentos sobre administração pública, e incentivar o acompanhamento pela sociedade da aplicação dos recursos públicos. Objetiva ainda criar condições para uma relação harmoniosa entre o Estado e o cidadão.

Atualmente o programa conta com alguns vieses, assim entendidos, as campanhas com objetivos específicos, destacando-se: Campanha Cidadão Nota 10, Nota Solidária, Show de Nota e o Cidadão sem Fome.

$\mathrm{O} \mathrm{PEF} / \mathrm{RN}$ tem como diretrizes:

\section{Enfase no exercício pleno da cidadania.}

2. O tratamento das questões tributárias e de finanças públicas deve abranger os três níveis de governo.

3. Caráter de permanência.

4. Programa desvinculado de campanhas.

5. A implementação conta com o apoio do Ministério da Fazenda e do Ministério da Educação.

6. A busca permanente do controle social (participação do cidadão na gestão governamental).

7. O conteúdo programático deve ser inserido na grade curricular, de forma transversal, conforme proposta dos Parâmetros Curriculares Nacionais.

REUNIR - Revista de Administração, Contabilidade e Sustentabilidade ISSN: 2237-3667 - Vol.3, no 4, Set./Dez., p. 39-61, 2013. 
Esses objetivos e diretrizes, aderentes ao Programa Nacional de Educação Fiscal, fazem parte de um contexto sócio-educacional que representa uma nova prática pedagógica, voltada a conscientização social do cidadão, materializadas através de campanhas e projetos permanentes, entre os quais se destacam a Campanha Cidadão Nota 10, voltada à melhoria da cultura, do esporte, da saúde e da assistência social.

Através da campanha o Estado já repassou para entidades cadastradas no programa através do viés Nota Solidária mais de $\mathrm{R} \$ 18$ milhões de reais ${ }^{4}$. O viés Nota Solidária é uma forma de estimular a efetiva participação do cidadão na fiscalização dos tributos e a emissão de documentos fiscais pelos contribuintes de ICMS. Atualmente são quase 210 entidades cadastradas no programa em todo o Estado do Rio Grande do Norte, atuando na área de saúde, esporte, cultura e assistência social.

As entidades cadastradas arrecadam documentos fiscais junto ao consumidor final, e recebem recursos públicos como premiação a cada quatro meses. Os critérios de distribuição são normatizados pela Secretaria de Tributação do RN e o dinheiro deve ser aplicado, conforme projeto validado pela gestão do $\mathrm{PEF} / \mathrm{RN}$, na aquisição de equipamentos, compra, construção e reformas de imóveis, sendo todos compatíveis com a atividade fim da entidade. Dos valores recebidos a entidade pode aplicar $30 \%$ do valor arrecadado nas despesas de custeio.

Além dos repasses financeiros, foram distribuídos mais de 400 mil ingressos destinados para shows, jogos de futebol, entradas para parques infantis, micaretas, teatro, entres outros eventos que foram trocados pelos cidadãos, através do viés Show de Nota, com um investimento total de $\mathrm{R} \$ 4.600 .000,00$ (quatro milhões e seiscentos mil reais). O Viés Nota solidária destina quadrimestralmente cerca de $\mathrm{R} \$$ 1,15 milhão para serem distribuídos entre as entidades, de acordo com o número de documentos fiscais arrecadados por elas no período.

O mais novo víeis do programa é o Cidadão sem Fome, que permite a troca de cupons e notas por alimentos. Implantado em agosto de 2009, tem atendido a população em 20 terminais espalhados pelas grandes zonas da cidade. Nessa campanha, os cidadãos que recolhem os documentos têm a possibilidade de trocar notas e cupons fiscais por cestas de alimentos. Uma das metas da campanha é a disseminação até o final de 2010, em pelo menos 14 cidades do Estado do RN, permitindo a distribuição de 30 mil cestas por mês.

O quadro 1 apresenta uma síntese do valores repassados as entidades no período de 2004 a 2009, sem considerar os incentivos individuais aos cidadãos. 
BORGES, E. F.; et al. Educação Fiscal, Terceiro Setor e Funções de Governo...

\begin{tabular}{|c|c|c|c|}
\hline \multicolumn{4}{|c|}{ Quadro 1 - Recursos distribuídos pelo PEF/RN - 2004 a 2009} \\
\hline Assistência Social & $9.318 .126,70$ & 2.801.164,89 & 12.119.291,59 \\
\hline Saúde & $2.447 .832,84$ & $679.270,50$ & 3.127.103,34 \\
\hline Cultura & $1.149 .992,70$ & $434.039,77$ & $1.584 .032,47$ \\
\hline Desporto e Lazer & $1.257 .956,66$ & $461.615,94$ & $1.719 .572,60$ \\
\hline TOTAL & $14.173 .908,90$ & $4.376 .091,10$ & $18.550 .000,00$ \\
\hline
\end{tabular}

Fonte: SET/RN

\subsection{Relação entre Estado, mercado e terceiro setor}

A distribuição de recursos pelo Estado para as entidades não governamentais materializa um eixo necessário ao cumprimento dos objetivos sociais inerentes à sociedade moderna. Olak e Nascimento (2006) entendem que a ligação entre Estado, mercado e terceiro setor é indispensável, concluindo que deve haver parcerias em suas atividades de forma independente e autônoma, sendo cada um livre no que se refere à sua gestão e tomada de decisões. Os autores também afirmam que a economia mundial tem buscado harmonia entre os três setores pela impossibilidade de que esses entes alcancem seus objetivos de forma isolada.

Matias-Pereira (2009a, p. 7), tratando dos desafios que a gestão pública deve ter no mundo contemporâneo, afirma:

\footnotetext{
A função principal do Estado-nação no mundo contemporâneo - realizada por meio do governo e da administração pública - é a de ampliar de forma sistemática as oportunidades individuais, institucionais e regionais. Deve preocupar-se, também, em gerar estímulos para facilitar a incorporação de novas tecnologias e inovações no setor público. Que proporcionem as condições exigidas para atender as demandas da sociedade contemporânea.
}

Por esses critérios, e pela demanda existentes por políticas sociais voltadas principalmente a educação, saúde e ao bem estar social, a atuação de entidades do terceiro setor complementa a ação estatal, que por sua vez deve alocar recursos a tais entidades, permitindo o cumprimento dos seus objetivos sociais conjuntamente.

Essa discussão é entendida como um efeito necessário do processo de redemocratização brasileiro a partir dos anos 90, que exige um modelo de Estado menos burocrático, mais flexível e eficiente, voltado ao atendimento do cidadão. Desse contexto, a palavra "parceria" surge como uma expressão de um novo padrão 
de relacionamento entre os três setores da sociedade, Estado, Mercado e Terceiro Setor.

Essas instituições possuem características próprias de atuação, sendo necessário, na visão de Ioschpe (2000, p. 43, apud Olak, 2000) que as mesmas não tenham fins lucrativos, sejam organizações voluntárias, formadas, total ou parcialmente, por cidadãos organizados voluntariamente; e o corpo técnico normalmente seja constituído por cidadãos ligados à organização por razões filosóficas. Sejam orientadas para a ação e comumente intermediárias entre o cidadão comum e entidades que podem participar da solução de problemas identificados.

Para Fischer (2002), assim como nas empresas, essas entidades gerenciam um conjunto de recursos - normalmente escassos - e buscam, incessantemente, a eficácia de suas atividades. Antes fechadas em si mesmas e em suas causas, essas organizações passaram a buscar novas formas de desenvolvimento de atividades, através da incorporação de preocupações com receitas, resultados, avaliações e qualidade em serviços, fatores que se tornaram cruciais à sustentabilidade, pontos comuns à gestão pública eficiente.

O aumento da atuação do Terceiro Setor, para Fonseca (2000, p. 4), cria uma relação íntima, formando uma tríade com o Estado e o Mercado, conforme representado na Figura 1.

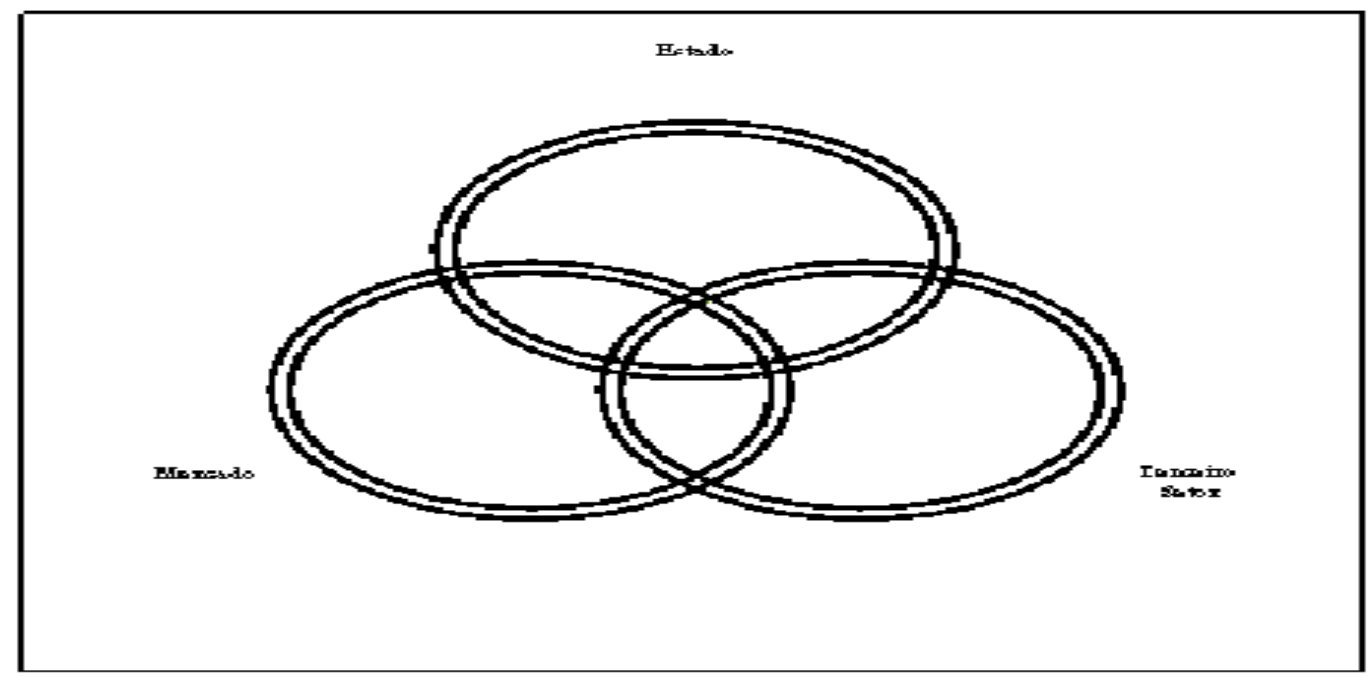

Fonte: Adaptada de Fonseca, 2000.

Essa relação, como processo simbiótico, facilita a ação estatal na formulação, implantação e gestão de políticas públicas, como é o caso da Política de Educação Fiscal. Através dessas entidades, o Estado alcança o cidadão nas suas necessidades 


\section{BORGES, E. F.; et al. Educação Fiscal, Terceiro Setor e Funções de Governo...}

básicas, e cumpre o que delimita a Constituição Federal quanto aos diretos fundamentais, proporcionando assistência social, cultura, educação e saúde.

Para Salamon (1998, p. 10) "o terceiro setor claramente chegou como um ator principal no cenário mundial, mas ainda está para marcar sua presença na consciência pública, no círculo de políticas, na mídia e na pesquisa acadêmica". Para a autora, apesar do crescimento na sua atuação, essas entidades ainda necessitam superar alguns desafios, considerando:

a) desafio da legitimidade: a ausência de informação disponível sobre o terceiro setor tem feito com que haja uma grande falta de consciência a seu respeito. Isso porque ele é, sistematicamente, ignorado nas estatísticas econômicas; poucas vezes referenciado nos debates políticos e nos meios de comunicação; além de não ter ainda despertado o interesse do meio acadêmico de forma a incentivar o desenvolvimento maciço de pesquisas; b) desafio da eficiência: trata-se da necessidade de o setor demonstrar sua capacidade e competência em um ambiente em que crescem as pressões para aperfeiçoar o sistema de administração, desempenho, controle institucional, etc; c) desafio da colaboração: desenvolver a colaboração com o Estado que, além de importante fonte de financiamento, é um poderoso parceiro no desenvolvimento de projetos em conjunto, visando ao cumprimento das demandas da sociedade no âmbito social. O terceiro setor não nasceu com o objetivo de substituir o Estado. No Brasil, o mecanismo da publicização utilizado no âmbito da reforma do Estado é um exemplo da aproximação do Estado em relação ao terceiro setor com o objetivo do desenvolvimento de projetos em conjunto; d) desafio da sustentabilidade: o problema da sustentabilidade abrange não só os aspectos financeiros, que têm trazido problemas de sobrevivência a esse grupo de entidades, mas também a sustentabilidade do capital humano, aqui caracterizado pelos profissionais que, muitas vezes, se afastam das entidades do terceiro setor, de colaboradores de empresas que desenvolvem atividades sociais como forma de demonstrar sua responsabilidade social perante os stakeholders.

Para Borges (2008), nas principais economias capitalistas, a maior visibilidade do Terceiro Setor está ligada à redefinição da atuação do Estado (com a crise do Welfare State) e à crise de emprego provocada pela revolução tecnológica. Em países periféricos, como o Brasil, apesar de nunca existir um Estado de bem-estar social, o Estado, tomado pela onda liberal dos anos 1980 e 1990, transferiu suas atribuições para a iniciativa privada.

Para a autora, esse "enxugamento" deu-se não somente no setor lucrativo, mas também no setor social, como educação, saúde, assistência social, entre outras políticas, obrigando a sociedade civil a se mobilizar e ocupar estas lacunas do Estado, expandindo assim a atuação do terceiro setor. Portanto, há que se esperar, pela

REUNIR - Revista de Administração, Contabilidade e Sustentabilidade ISSN: 2237-3667 - Vol.3, no 4, Set./Dez., p. 39-61, 2013. 
BORGES, E. F.; et al. Educação Fiscal, Terceiro Setor e Funções de Governo...

afirmação, que os indicadores sociais estatais tenham reflexo nas ações e investimentos tomados por essas entidades.

\section{PROCEDER METODOLÓGICO}

A seguir são apresentados os aspectos metodológicos aplicados no trabalho, destacando-se o tipo de pesquisa, população e a amostra objeto do estudo, os instrumentos de coleta, as formas de tratamento e análise dos dados e as limitações do estudo.

\subsection{Tipo de Pesquisa}

A pesquisa é tipificada como descritiva, dada a necessidade de observar, analisar e correlacionar às variáveis do estudo, (CERVO; BERVIAN; SILVA, 2007). Esses autores delimitam que as pesquisas descritivas buscam conhecer as diversas situações e relações que ocorrem na vida social, política, econômica, e nos demais comportamentos do homem, tanto na sua vida particular como em grupos e comunidades mais complexas. Para Gil (2006), essas pesquisas, associadas às exploratórias, são as mais utilizadas pelos pesquisadores sociais que têm uma preocupação com a prática.

\subsection{População, amostra e procedimentos de coleta de dados}

A população desta pesquisa é formada pelos 167 (cento e sessenta e sete) municípios do Estado do Rio Grande do Norte e a amostra é composta pelos municípios que representam o domicílio das entidades de terceiro setor beneficiadas pelos repasses do PEF/RN, totalizando 40 (quarenta) municípios.

Os dados relativos aos repasses feitos pelo PEF/RN às entidades foram coletados junto a gerência geral do $\mathrm{PEF} / \mathrm{RN}$, que através de relatório circunstanciado, aderente as informações prestados no sítio oficial (www.cidadãonota10.rn.gov.br) identificou todos os beneficiados por município, montante e espécie social (saúde, assistência social, cultura, desporto e lazer).

Para o cálculo dos indicadores das funções de governo, efetuou-se uma busca junto ao sítio da Secretaria do Tesouro Nacional (STN) (www.stn.gov.br), de onde foram extraídas as informações bases para os índices. Como nem todas as informações relativas ao quantitativo populacional dos municípios estavam sintetizadas no sitio da STN, foram feitas várias buscas junto ao Instituto Brasileiro 
BORGES, E. F.; et al. Educação Fiscal, Terceiro Setor e Funções de Governo...

de Geografia e Estatística (IBGE) (www.ibge.gov.br), a fim de obter a população estimada desses municípios.

\subsection{Definição das variáveis analisadas}

A avaliação do nível de eficiência na gestão econômica e financeira dos recursos públicos geralmente considera a análise das demonstrações contábeis das prefeituras. Por determinação legal, prefeituras e câmaras municipais são obrigadas a informar semestralmente seus dados contábeis à Secretaria de Tesouro Nacional STN, que são disponibilizados em forma de relatórios.

Cruz (2008) apresenta uma série que pode ser usada na avaliação da gestão de recursos municipais, qualificando-os sob dois conceitos básicos, a) indicadores monetários e b) indicadores relativos. Os indicadores monetários são expressos em valores monetários e necessitam do valor presente para poder oferecer consistência frente ao pressuposto de comparabilidade. Os indicadores relativos não exigem o conhecimento do valor, pois evidenciam o percentual de participação relativa, quando comparado a outra gestão ou mesmo entre diferentes períodos de tempo.

Esses indicadores evidenciam o atendimento as determinações constitucionais quanto a alocação de recursos segundo os princípios da administração pública, priorizando as funções saúde, habitação, educação, saneamento básico, segurança e incentivos.

Para a pesquisa, a partir dos índices de avaliação da gestão de recursos públicos já validados na literatura, especificamente os que analisam as funções de governo, componentes do Modelo de Análise de Desempenho Municipal do Núcleo de Indicadores Contábeis Brasileiros - ICB da Universidade Federal de Santa Catarina (disponível em: www.nicb.ufsc.br), foram desenvolvidos 5 (cinco) indicadores básicos, adotando-se uma metodologia simplificada para seu cálculo, que considera o valor dos gastos com cada função, divididos pela população média dos municípios pesquisados.

Os conceitos subjacentes aos componentes dos indicadores levam em consideração o disposto na Lei 4.320/64, e nos trabalhos de Scarpin (2006), Cruz (2008); Slomski (2008); NICB'S, (2010), e representam:

$\checkmark$ Indicador Geral das Funções de Governo (IGFG): Considera o total dos gastos com as funções de governo, divididos pela população média do mesmo período;

$\checkmark$ Indicador de Gastos com Assistência Social (IGAS): Considera a média dos gastos com a função Assistência Social nos exercícios analisados, divididos pela população média do mesmo período;

REUNIR - Revista de Administração, Contabilidade e Sustentabilidade ISSN: 2237-3667 - Vol.3, no 4, Set./Dez., p. 39-61, 2013. 
BORGES, E. F.; et al. Educação Fiscal, Terceiro Setor e Funções de Governo...

$\checkmark$ Indicador de Gastos com Saúde (IGS): Considera a média dos gastos com a função saúde nos exercícios analisados, divididos pela população média do mesmo período;

$\checkmark$ Indicador de Gastos com Cultura (IGC): Considera a média dos gastos com a função Cultura nos exercícios analisados divididos pela população média do mesmo período;

$\checkmark$ Indicador de Gastos com Desporto e Lazer Esportes (IGDL): Considera a média dos gastos com a função Desporto e Lazer nos exercícios analisados divididos pela população média do mesmo período;

\subsection{Definição do modelo e pressupostos assumidos}

No contexto de discussão sobre a influência da educação fiscal sobre os indicadores das funções de governo, elabora-se um modelo conceitual que permita uma base subjacente as análises dos resultados dos testes das hipóteses previstas, sendo operacionalizadas por um modelo a partir de teste de hipóteses.

Esse processo considera as premissas estabelecidas por Martins (2005) quanto à parcimônia necessária no seu estabelecimento, uma vez que o processo de simplificação da realidade é um problema inerente à formulação de modelos, pois este pode vir a omitir fatores relevantes à compreensão do fenômeno estudado, (MAZZON, 1978; MARTINS, 2005).

Essa característica exige do pesquisador uma base científica que lhe permita o discernimento necessário ao processo de formulação e interpretação do modelo, como adequado ou não a realidade observada, respaldando, alterando ou propondo novos pressupostos (ou teorias) a partir de suas constatações.

Um modelo é constituído com poucas variáveis-fatores manejáveis de tal sorte que as relações mais significantes possam ser identificadas e estudadas (MAZZON, 1978; MARTINS, 2005).

Para Paulo (2005) o desenvolvimento e a posterior aplicação dos modelos é uma necessidade para a evolução da pesquisa científica contábil. Por esse pressuposto, essa seção objetiva apresentar os principais aspectos relacionados ao modelo analítico-empírico adotado para o trabalho.

$\checkmark$ Pressuposto Geral Assumido: A Educação Fiscal, através dos repasses efetuados pelo PEF/RN, influencia positivamente os indicadores sociais e de Função de Governo dos Municípios Potiguares.

As hipóteses consideram como base de comparação as médias dos indicadores estudados, uma vez que os repasses às entidades beneficiadas pelo PEF/RN teve 
BORGES, E. F.; et al. Educação Fiscal, Terceiro Setor e Funções de Governo...

início no ano de 2004, motivo pelo qual se comparam os resultados dos dois períodos.

Como elemento facilitador, elaborou-se o quadro 2, que traz uma matriz de amarração da pesquisa (MAZZON, 1978; TELLES, 2001; MARTINS, 2005):

Quadro 2 - Matriz de amarração da pesquisa

\begin{tabular}{|c|c|c|c|}
\hline $\begin{array}{c}\text { MODELO TEÓRICO E } \\
\text { PRESSUPOSTOS } \\
\text { ASSUMIDOS }\end{array}$ & $\begin{array}{c}\text { PROBLEMA DE } \\
\text { PESQUISA }\end{array}$ & $\begin{array}{c}\text { HIPÓTESES } \\
\text { PESQUISA }\end{array}$ & $\begin{array}{l}\text { TÉCNICA } \\
\text { DE } \\
\text { ANÁLISE }\end{array}$ \\
\hline $\begin{array}{l}\text { A Educação Fiscal influencia } \\
\text { positivamente } \\
\text { Indicadores Sociais e de } \\
\text { Função de Governo dos } \\
\text { Municípios Potiguares. }\end{array}$ & $\begin{array}{l}\text { Existe relação entre o } \\
\text { Programa r de } \\
\text { Educação Fiscal do } \\
\text { RN (PEF/RN) e os } \\
\text { indicadores sociais } \\
\text { dos municípios } \\
\text { alcançados } \\
\text { programa? }\end{array}$ & $\begin{array}{l}\text { Ho - Não há diferença entre as } \\
\text { médias dos indicadores sociais } \\
\text { e das funções de governo dos } \\
\text { municípios domicílios das } \\
\text { entidades beneficiadas antes } \\
\text { dos repasses do PEF/RN e as } \\
\text { médias dos indicadores } \\
\text { posteriores aos repasses. } \\
\text { H1-As médias dos indicadores } \\
\text { sociais e das funções de } \\
\text { governo dos municípios } \\
\text { domicílios das entidades } \\
\text { beneficiadas pelos repasses do } \\
\text { PEF/RN são diferentes das } \\
\text { médias dos indicadores } \\
\text { posteriores aos repasses. }\end{array}$ & $\begin{array}{l}\text { Teste de } \\
\text { Hipóteses }\end{array}$ \\
\hline
\end{tabular}

Fonte: Adaptado de Mazzon (1978)

\section{APRESENTAÇÃO E DISCUSSÃO DOS RESULTADOS}

A análise dos dados resultantes das observações efetuadas procede com o auxílio do teste de hipóteses segundo a fundamentação estatística de Stevenson (1981). Para a pesquisa foram delimitadas as seguintes hipóteses de pesquisa:

$H_{0}$ - Não há diferença entre as médias dos indicadores das funções de governo dos municípios domicílios das entidades beneficiadas antes dos repasses do PEF/RN e as médias dos indicadores posteriores aos repasses.

$H_{1}$ - As médias dos indicadores das funções de governo dos municípios domicúlios das entidades beneficiadas pelos repasses do PEF/RN são diferentes das médias dos indicadores posteriores aos repasses.

A amostra inicial considerava os 40 (quarenta) municípios sedes das entidades do terceiro setor beneficiárias pelos recursos advindos do $P E F / R N$, mas a 
sumarização das informações orçamentárias entre os exercícios de 2004 a 2009 só foi possível em 34 (trinta e quatro) desses, uma vez que nos 6 restantes algumas informações, em determinados exercícios, não estavam disponíveis no site da STN. Por esse motivo foram excluídos da amostra os municípios de Currais Novos, Governador Dix-Sept- Rosado, Macau, Rio do Fogo e São José de Campestre.

Sobre a amostra resultante foram calculados os indicadores tomando as seguintes diretrizes:

a) Cálculo dos indicadores considerando o total das despesas do período com assistência social, saúde, cultura e desporto, divididas pela população média do município, entre o período de 2004 a 2009;

b) Repetição do cálculo dos indicadores agregando os montantes recebidos do PEF pelas ONG'S de cada município (apresentados no quadro 1).

Objetivando minimizar eventuais discrepâncias na análise dos indicadores entre os municípios, optou-se por segregá-los em cinco estratos, considerando a população média de cada um, conforme se apresenta nas Tabelas 1 a 10, que também traz os indicadores médios calculados conforme a metodologia anteriormente apresentada com os dados orçamentários (Tabelas 1 a 5), e com os dados orçamentários somados aos repasses do PEF/RN (Tabelas 6 a 10).

Tabela 1 - Municípios -População Inferior a 10000hab

\begin{tabular}{l|rr|r|r|r|r}
\hline \multicolumn{1}{c|}{ Município } & População & \multicolumn{1}{c|}{ IGFG } & IGAS & \multicolumn{1}{c|}{ IGS } & \multicolumn{1}{c}{ IGC } & IGDL \\
\hline CARNAÚBA DOS DANTAS & 7083,17 & 932,20 & 88,15 & 223,00 & 21,05 & 20,73 \\
CRUZETA & 8132,83 & 784,66 & 56,74 & 195,13 & 24,41 & 10,94 \\
ENCANTO & 5062,67 & 1284,62 & 80,06 & 346,05 & 0,00 & 23,04 \\
FLORÂNIA & 8692,33 & 749,57 & 41,88 & 192,26 & 6,95 & 12,54 \\
LUÍS GOMES & 9744,17 & 976,92 & 52,03 & 195,09 & 14,47 & 3,88 \\
OURO BRANCO & 4913,17 & 1078,00 & 45,10 & 244,57 & 59,08 & 1,09 \\
PORTALEGRE & 6994,83 & 971,05 & 65,54 & 225,66 & 4,36 & 8,20 \\
\hline
\end{tabular}

Tabela 2 - Municípios -População entre 10001 a 200000hab

\begin{tabular}{lrrrrrrrr}
\hline \multicolumn{1}{c}{ Município } & População & \multicolumn{1}{c}{ IGFG } & IGAS & \multicolumn{1}{c}{ IGS } & \multicolumn{1}{c}{ IGC } & IGDL \\
\hline ACARÍ & 11217,17 & 795,25 & 50,56 & 186,80 & 8,11 & 4,28 \\
AFONSO BEZERRA & 10736,17 & 832,65 & 50,04 & 216,41 & 1,61 & 0,79 \\
ALEXANDRIA & 13633,67 & 858,97 & 53,81 & 173,49 & 17,51 & 7,34 \\
CARAÚBAS & 19062,67 & 971,15 & 35,64 & 182,12 & 29,59 & 15,46 \\
JARDIM DO SERIDÓ & 12209,17 & 764,66 & 45,41 & 168,59 & 24,03 & 10,03 \\
LAGOA NOVA & 13158,50 & 856,45 & 31,14 & 191,08 & 0,00 & 1,44 \\
LAJES & 10254,67 & 844,89 & 93,70 & 168,06 & 12,52 & 2,20 \\
S. PAULO DO POTENGI & 14969,00 & 864,19 & 64,12 & 225,89 & 8,27 & 5,84 \\
SÃO TOMÉ & 10865,50 & 890,10 & 109,95 & 161,05 & 11,10 & 5,46
\end{tabular}

REUNIR - Revista de Administração, Contabilidade e Sustentabilidade ISSN: 2237-3667 - Vol.3, no 4, Set./Dez., p. 39-61, 2013. 
BORGES, E. F.; et al. Educação Fiscal, Terceiro Setor e Funções de Governo...

TIBAU DO SUL

$\begin{array}{llllll}10101,67 & 1246,05 & 36,66 & 273,13 & 9,80 & 16,85\end{array}$

Tabela 3 - Municípios -População entre 20001 a 300000hab

\begin{tabular}{l|r|r|r|r|r|r}
\hline \multicolumn{1}{c|}{ Município } & \multicolumn{1}{c|}{ População } & \multicolumn{1}{c|}{ IGFG } & IGAS & \multicolumn{1}{c|}{ IGS } & \multicolumn{1}{c}{ IGC } & IGDL \\
\hline AREIA BRANCA & 24166,17 & 1552,70 & 92,89 & 263,58 & 13,57 & 19,50 \\
EXTREMOZ & 22410,17 & 920,60 & 29,85 & 148,97 & 3,25 & 2,48 \\
MONTE ALEGRE & 20935,33 & 668,70 & 32,23 & 167,46 & 16,48 & 0,00 \\
PARELHAS & 20408,83 & 719,43 & 34,79 & 197,31 & 2,95 & 4,94 \\
PAU DOS FERROS & 27290,33 & 766,16 & 49,01 & 221,78 & 12,29 & 6,21 \\
\hline
\end{tabular}

Tabela 4 - Municípios -População entre 30001 a 400000hab

\begin{tabular}{l|c|c|c|c|c|r}
\hline \multicolumn{1}{c|}{ Município } & População & IGFG & IGAS & IGS & IGC & IGDL \\
\hline APODI & 35701,50 & 734,97 & 36,20 & 139,26 & 7,06 & 13,29 \\
SANTA CRUZ & 33739,83 & 791,73 & 71,05 & 205,59 & 4,12 & 21,28 \\
S. JOSÉ DE MIPIBU & 38469,83 & 777,95 & 40,37 & 212,52 & 7,80 & 0,00 \\
TOUROS & 31078,00 & 815,07 & 32,36 & 200,95 & 0,87 & 0,43 \\
\hline
\end{tabular}

Tabela 5 - Municípios -População acima de 400000hab

\begin{tabular}{l|rr|r|r|rr}
\hline \multicolumn{1}{c|}{ Município } & \multicolumn{1}{c|}{ População } & \multicolumn{1}{c|}{ IGFG } & \multicolumn{1}{c|}{ IGAS } & \multicolumn{1}{c|}{ IGS } & \multicolumn{1}{c}{ IGC } & IGDL \\
\hline ASSU & 51529,00 & 713,52 & 53,70 & 139,32 & 5,66 & 1,89 \\
CAICÓ & 61522,50 & 624,41 & 28,68 & 222,29 & 13,54 & 3,32 \\
CEARÁ MIRIM & 67889,17 & 731,88 & 22,13 & 179,50 & 3,24 & 2,67 \\
MACAÍBA & 63535,50 & 865,72 & 16,74 & 186,24 & 15,44 & 21,94 \\
MOSSORÓ & 233729,67 & 990,99 & 36,18 & 292,00 & 26,01 & 4,64 \\
NATAL & 785415,00 & 1042,14 & 27,36 & 244,72 & 7,39 & 16,27 \\
PARNAMIRIM & 170857,33 & 897,11 & 39,37 & 206,42 & 5,35 & 1,95 \\
S. G. AMARANTE & 82026,67 & 794,08 & 46,46 & 182,06 & 7,21 & 1,90 \\
\hline
\end{tabular}

Tabela 6 - Municípios -População Inferior a 10000hab - Com Repasses

\begin{tabular}{l|r|r|r|r|r|r}
\hline \multicolumn{1}{c|}{ Município } & População & \multicolumn{1}{c|}{ IGFG } & \multicolumn{1}{c}{ IGAS } & \multicolumn{1}{c}{ IGS } & \multicolumn{1}{c}{ IGC } & IGDL \\
\hline CARNAÚBA DOS DANTAS & 7083,17 & 934,74 & 88,30 & 225,39 & 21,05 & 20,73 \\
CRUZETA & 8132,83 & 785,39 & 56,74 & 195,13 & 24,41 & 10,94 \\
ENCANTO & 5062,67 & 1285,51 & 80,06 & 346,05 & 0,00 & 23,04 \\
FLORÂNIA & 8692,33 & 749,96 & 41,88 & 192,66 & 6,95 & 12,54 \\
LUÍS GOMES & 9744,17 & 976,93 & 52,03 & 195,09 & 14,48 & 3,88 \\
OURO BRANCO & 4913,17 & 1078,02 & 45,12 & 244,57 & 59,08 & 1,09 \\
PORTALEGRE & 6994,83 & 976,40 & 65,54 & 226,05 & 9,33 & 8,20 \\
\hline
\end{tabular}

Tabela 7 - Municípios -População entre 10001 a 200000hab - Com Repasses

\begin{tabular}{l|r|r|r|r|r|r}
\hline \multicolumn{1}{c|}{ Município } & População & IGFG & IGAS & \multicolumn{1}{c|}{ IGS } & \multicolumn{1}{c|}{ IGC } & IGDL \\
\hline ACARÍ & 11217,17 & 797,23 & 50,56 & 188,78 & 8,11 & 4,28 \\
AFONSO BEZERRA & 10736,17 & 832,71 & 50,04 & 216,48 & 1,61 & 0,79 \\
ALEXANDRIA & 13633,67 & 859,10 & 53,81 & 173,49 & 17,64 & 7,34 \\
CARAÚBAS & 19062,67 & 971,35 & 35,85 & 182,12 & 29,59 & 15,46 \\
JARDIM DO SERIDÓ & 12209,17 & 769,15 & 48,51 & 169,97 & 24,03 & 10,03
\end{tabular}

REUNIR - Revista de Administração, Contabilidade e Sustentabilidade

ISSN: 2237-3667 - Vol.3, no 4, Set./Dez., p. 39-61, 2013. 
BORGES, E. F.; et al. Educação Fiscal, Terceiro Setor e Funções de Governo...

\begin{tabular}{lrrrrrr} 
LAGOA NOVA & 13158,50 & 856,46 & 31,14 & 191,08 & 0,00 & 1,44 \\
LAJES & 10254,67 & 845,23 & 93,70 & 168,40 & 12,52 & 2,20 \\
S. PAULO DO POTENGI & 14969,00 & 864,32 & 64,25 & 225,89 & 8,27 & 5,84 \\
SÃO TOMÉ & 10865,50 & 891,30 & 111,15 & 161,05 & 11,10 & 5,46 \\
TIBAU DO SUL & 10101,67 & 1246,05 & 36,66 & 273,13 & 9,80 & 16,85 \\
\hline
\end{tabular}

Tabela 8 - Municípios -População entre 20001 a 300000hab - Com Repasses

\begin{tabular}{l|r|r|r|r|r|r}
\hline \multicolumn{1}{c}{ Município } & \multicolumn{1}{c|}{ População } & \multicolumn{1}{c|}{ IGFG } & \multicolumn{1}{c}{ IGAS } & \multicolumn{1}{c|}{ IGS } & \multicolumn{1}{|c|}{ IGC } & IGDL \\
\hline AREIA BRANCA & 24166,167 & 1552,72 & 92,89 & 263,58 & 13,57 & 19,51 \\
EXTREMOZ & 22410,167 & 921,13 & 30,38 & 148,97 & 3,25 & 2,48 \\
MONTE ALEGRE & 20935,333 & 668,92 & 32,23 & 167,46 & 16,48 & 0,00 \\
PARELHAS & 20408,833 & 722,04 & 34,98 & 197,62 & 2,95 & 7,05 \\
PAU DOS FERROS & 27290,333 & 767,60 & 50,22 & 221,78 & 12,29 & 6,43 \\
\hline
\end{tabular}

Tabela 9 - Municípios -População entre 30001 a 400000hab - Com Repasses

\begin{tabular}{l|c|c|c|c|c|r}
\hline \multicolumn{1}{c|}{ Município } & População & IGFG & IGAS & IGS & IGC & IGDL \\
\hline APODI & 35701,50 & 735,20 & 36,20 & 139,26 & 7,29 & 13,29 \\
SANTA CRUZ & 33739,83 & 791,96 & 71,05 & 205,82 & 4,12 & 21,28 \\
S. JOSÉ DE MIPIBU & 38469,83 & 779,78 & 41,72 & 212,52 & 7,80 & 0,47 \\
TOUROS & 31078,00 & 815,18 & 32,47 & 200,95 & 0,87 & 0,43 \\
\hline
\end{tabular}

Tabela 10 - Municípios -População acima de 400000hab - Com Repasses

\begin{tabular}{l|r|r|r|r|r|r}
\hline \multicolumn{1}{c|}{ Município } & \multicolumn{1}{c|}{ População } & \multicolumn{1}{c|}{ IGFG } & IGAS & \multicolumn{1}{c}{ IGS } & IGC & IGDL \\
\hline ASSU & 51529,00 & 713,72 & 53,70 & 139,32 & 5,86 & 1,89 \\
CAICÓ & 61522,50 & 625,67 & 29,50 & 222,74 & 13,54 & 3,32 \\
CEARÁ MIRIM & 67889,17 & 732,09 & 22,35 & 179,50 & 3,24 & 2,67 \\
MACAÍBA & 63535,50 & 866,89 & 17,38 & 186,24 & 15,51 & 22,39 \\
MOSSORÓ & 233729,67 & 992,01 & 36,18 & 292,00 & 26,01 & 4,64 \\
NATAL & 785415,00 & 1044,48 & 28,99 & 245,16 & 7,45 & 16,48 \\
PARNAMIRIM & 170857,33 & 898,72 & 40,83 & 206,42 & 5,35 & 2,10 \\
S. G. AMARANTE & 82026,67 & 794,35 & 46,46 & 182,33 & 7,21 & 1,90 \\
\hline
\end{tabular}

Fonte: Dados da pesquisa.

Utilizando a ferramenta Análise de Dados integrante do Excel ${ }^{\circledR}$, que compõe o pacote Office da Microsoft (2007), efetuou-se o teste $t$ para amostras emparelhadas para cada função estudada, cujos resultados (p-value) estão sintetizados na Tabela 11. Para a análise foi estabelecido um nível de significância em 5\% $(\alpha=0,05)$

REUNIR - Revista de Administração, Contabilidade e Sustentabilidade ISSN: 2237-3667 - Vol.3, no 4, Set./Dez., p. 39-61, 2013. 
BORGES, E. F.; et al. Educação Fiscal, Terceiro Setor e Funções de Governo...

Tabela 11 - Significância Estatística dos Indicadores Gerais

\begin{tabular}{lrr}
\hline \multicolumn{1}{c}{ Indicador } & $\mathrm{P}(\mathrm{T}<=\mathrm{t})$ uni-caudal & $\mathrm{P}(\mathrm{T}<=\mathrm{t})$ bi-caudal \\
\hline FG - Gerais & $7,04852 \mathrm{E}-05$ & 0,00014097 \\
IGAS & 0,001391438 & 0,002782877 \\
IGS & 0,010574766 & 0,021149533 \\
IGC & 0,131349171 & 0,262698342 \\
IGDL & 0,052345966 & 0,104691932 \\
\hline
\end{tabular}

Fonte: Dados da pesquisa.

A primeira análise foi feita comparando-se as médias gerais dos indicadores das amostras com e sem os repasses. Por esses resultados, confirma-se o pressuposto inicial assumido para as hipóteses de pesquisas, quanto a influência positiva sobre os indicadores das funções, especificamente com as funções de assistência social, saúde e desporto e lazer, materializando os fundamentos apontados pelo Programa Nacional de Educação Fiscal e os do PEF/RN.

Tachizawa (2004) apresenta as principais categorias beneficiadas com a atuação dessas entidades, sendo a maior parcela de crianças e adolescentes. Essa afirmação encontra ponto frente aos resultados, tendo em vista que o total de recursos repassados pelo PEF/RN entre 2004 e 2009, alcançaram 135 entidades de assistência social, 35 voltadas à cultura, 31 ao esporte e 24 à saúde, todas com maior foco de atenção às crianças e adolescentes.

Considerando a eventual influência dos indicadores dos municípios entre si, uma vez que há uma variabilidade de orçamentos e contextos populacionais, foram realizados testes considerando os estratos apontados na tabela 12, dividindo-se os municípios em função do seu contingente populacional, sendo:

Aplicando-se os mesmos procedimentos para os indicadores gerais, obtiveram-se os seguintes resultados, por níveis de significância, conforme Tabela 12.

Tabela 12 - Significância estatística dos indicadores por estratos

\begin{tabular}{|c|c|c|c|}
\hline Estrato & Indicador & $\mathrm{P}(\mathrm{T}<=\mathrm{t})$ uni-caudal & $\mathrm{P}(\mathrm{T}<=\mathrm{t})$ bi-caudal \\
\hline \multirow{5}{*}{$\begin{array}{l}\text { População até } \\
\text { 10000hab. }\end{array}$} & FG - Gerais & 0,100031715 & 0,20006343 \\
\hline & IGAS & 0,181608734 & 0,363217468 \\
\hline & IGS & 0,087371494 & 0,174742988 \\
\hline & IGC & 0,181271604 & 0,362543207 \\
\hline & IGDL & - & - \\
\hline \multirow{5}{*}{$\begin{array}{l}\text { População entre } \\
10001 \text { a } 20.000 \text { hab }\end{array}$} & FG - Gerais & 0,086055717 & 0,172111434 \\
\hline & IGAS & 0,088391927 & 0,176783855 \\
\hline & IGS & 0,114690256 & 0,229380512 \\
\hline & IGC & 0,173296754 & 0,346593507 \\
\hline & IGDL & - & - \\
\hline População entre & FG - Gerais & 0,05533752 & 0,11067504 \\
\hline
\end{tabular}

REUNIR - Revista de Administração, Contabilidade e Sustentabilidade ISSN: 2237-3667 - Vol.3, no 4, Set./Dez., p. 39-61, 2013. 
BORGES, E. F.; et al. Educação Fiscal, Terceiro Setor e Funções de Governo...

\begin{tabular}{|c|c|c|c|}
\hline \multirow[t]{4}{*}{20001 a 30.000hab } & IGAS & 0,082568312 & 0,165136624 \\
\hline & IGS & 0,195501109 & 0,391002218 \\
\hline & IGC & - & - \\
\hline & IGDL & 0,168491131 & 0,336982262 \\
\hline \multirow{5}{*}{$\begin{array}{l}\text { População entre } \\
30001 \text { a } 40.000 \text { hab }\end{array}$} & FG - Gerais & 0,159825931 & 0,319651863 \\
\hline & IGAS & 0,188350514 & 0,376701028 \\
\hline & IGS & 0,211324865 & 0,422649731 \\
\hline & IGC & - & - \\
\hline & IGDL & 0,211324865 & 0,422649731 \\
\hline \multirow{5}{*}{$\begin{array}{c}\text { População acima de } \\
\text { 40000hab. }\end{array}$} & FG - Gerais & 0,00344592 & 0,006891839 \\
\hline & IGAS & 0,017812355 & 0,03562471 \\
\hline & IGS & 0,043309694 & 0,086619388 \\
\hline & IGC & 0,086200921 & 0,172401843 \\
\hline & IGDL & 0,062966798 & 0,125933595 \\
\hline
\end{tabular}

Fonte: Dados da pesquisa.

A análise por estratos mostrou que os indicadores dos municípios com populações superiores a 50.000 habitantes são impactados positivamente em função do recebimento de repasses por parte das entidades de Terceiro setor, quando comparados aos resultados da análise geral feita com os municípios com populações menores. Essa constatação talvez seja fruto da concentração de entidades na capital do Estado e demais municípios que compõem a região metropolitana (158 entidades). Por estar presente nas áreas mais desenvolvidas, o acesso as campanhas e aos meios informativos, acabam por favorecer sua atuação. É na capital e região metropolitana que se concentram, da mesma forma, a maioria dos estabelecimentos comerciais, que permitem a arrecadação dos documentos fiscais necessários ao recebimento dos repasses.

Além desses aspectos, existe um protocolo próprio que deve ser obedecido pelos interessados, desde o aspecto cadastral ao efetivo recebimento dos recursos, que por vezes exigem dos participantes o deslocamento de seus municípios sede para as unidades fiscais que concentram as ações do PEF/RN.

Apesar dessas limitações, percebe-se que as ações dessas entidades interferem diretamente na vida das pessoas, e ajuda o Estado a consolidar seus objetivos, frente as suas funções, o que de certa forma confirma as bases apontadas pela ESAF quanto à importância da educação fiscal para o governo e a sociedade.

REUNIR - Revista de Administração, Contabilidade e Sustentabilidade ISSN: 2237-3667 - Vol.3, no 4, Set./Dez., p. 39-61, 2013. 
BORGES, E. F.; et al. Educação Fiscal, Terceiro Setor e Funções de Governo...

\section{CONSIDERAÇÕES FINAIS}

Ao longo deste trabalho buscou-se demonstrar o impacto causado nos indicadores sociais das funções de governo dos municípios sedes das entidades de terceiro setor beneficiárias dos repasses do Programa de Educação Fiscal do RN (PEF/RN) entre os exercícios 2004 e 2009. Os resultados indicam que de maneira geral houve variação positiva nos indicadores, com reflexo direto sobre as funções de assistência social, saúde, desporto e lazer, confirmando a hipótese alternativa de pesquisa, de que as médias desses indicadores são diferentes daquelas posteriores aos repasses. Quando segregada a amostra em estratos, em função do contingente populacional, evidencia-se novamente a hipótese alternativa, demonstrando que o impacto conseqüente é concentrado nos municípios com populações superiores a 50.000 habitantes.

Como demonstrado, as entidades cadastradas no PEF/RN devem arrecadar documentos fiscais junto ao consumidor final para receber recursos públicos. A concentração econômica na capital e região metropolitana de Natal acaba por influenciar os indicadores, quando a análise segregou os municípios por faixa populacional.

Essa limitação abre espaço para novas pesquisas, que podem ter por objetivo verificar quais são as principais dificuldades enfrentadas para a captação dos recursos, considerando os aspectos cadastrais, o acesso a informações, entidades parceiras e entre outros. Outras pesquisas também podem investigar a efetividade na aplicação dos gastos, o impacto do programa na formação educacional da população e o que pensam os cidadãos dos municípios sedes sobre a atuação das entidades.

\section{REFERÊNCIAS}

BORGES, G. M. da C.. Imagens do terceiro setor: um estudo com pais e responsáveis financeiros das organizações educacionais. 2008. 102f. Dissertação (Mestrado em Administração) - Programa de Pós-Graduação em Administração da Universidade Federal do Rio Grande do Norte, Natal, 2008.

BORGES, E. F; NASCIMENTO, V. C; COSTA, F. M. de S.; COSTA, G. M. Uma visão exploratória da educação fiscal presente na formação do graduando em ciências contábeis da Universidade Federal do Rio Grande do Norte. Revista Brasileira de Contabilidade, Brasília, v. 1, no. 174, p. 69-83, nov./dez, 2008. 
BORGES, E. F.; et al. Educação Fiscal, Terceiro Setor e Funções de Governo...

BRASIL. Constituição Federal (1988). Constituição da República Federativa do

Brasil: promulgada em 5 de outubro de 1988. Brasília: Senado Federal, Subsecretaria de Edições Técnicas, 2000.

BRASIL. INSTITUTO BRASILEIRO DE GEOGRAFIA E ESTATÍSTICA - IBGE. O Brasil estado por estado. Rio de Janeiro: IBGE, 2009. Disponível em: $<$ http://www.ibge.gov.br/estadosat/perfil.php?sigla=rn>. Acesso em: 30 mar. 2010.

BRASIL. INSTITUTO BRASILEIRO DE GEOGRAFIA E ESTATÍSTICA - IBGE. Indicadores sociais. Rio de Janeiro: IBGE, 2009. Disponível em: $<$ http://www.ibge.gov.br>. Acesso em: 30 mar. 2010.

Ministério da Fazenda; Ministério da Educação. Escola de Administração Fazendária. Programa Nacional de Educação Fiscal: Educação fiscal no contexto social (Série Educação Fiscal. Cadernos). Brasília, 2004. Disponível em: <http://www.esaf.fazenda.gov.br/parcerias/educacao-fiscal/caderno/caderno_1.pdf>. Acesso em: 30 mar. 2010.

. Programa Nacional de Educação Fiscal. Por que a nossa sociedade precisa abraçar este programa. Disponível em: <www8.pr.gov.br/portals/portal/educacaofiscal/ppt/educacao_fiscaltributo_e_justica_social.ppt>. Acesso em: 30 mar. 2010.

- Receita Federal. Educação fiscal: uma prática possível e necessária. Disponível em: <http://www.receita.fazenda.gov.br/EducaFiscal/default.htm>. Acesso em: 30 mar. 2010.

Superintendência da Receita Federal. Programa Nacional de Educação Fiscal. O papel da Justiça Fiscal em um país de contrastes. Minas Gerais. Disponível em: $<$ http://www.esaf.fazenda.gov.br/parcerias/educacao-fiscal/programa.pdf $>$ Acesso em: 30 mar. 2010.

Lei 4.320, de 17 de março de 1964. Estatui Normas Gerais de Direito Financeiro para elaboração e controle dos orçamentos e balanços da União, dos Estados, dos Municípios e do Distrito Federal. Disponível em <www.planalto.gov.br>. Acesso em: 27 mar. 2010.

REUNIR - Revista de Administração, Contabilidade e Sustentabilidade ISSN: 2237-3667 - Vol.3, no 4, Set./Dez., p. 39-61, 2013. 
BORGES, E. F.; et al. Educação Fiscal, Terceiro Setor e Funções de Governo...

. Lei Complementar 101, de 04 de maio de 2000. Estabelece normas de finanças públicas voltadas para a responsabilidade na gestão fiscal e dá outras providências. Disponível em <www.planalto.gov.br>. Acesso em: 27 mar. 2010.

CERVO, A. L.; BERVIAN, A. Metodologia científica: para uso dos estudantes universitários. 3. ed. São Paulo: McGraw-Hill do Brasil, 1983.

CRUZ, F. da. Auditoria governamental. 3. ed. São Paulo:Atlas, 2008.

FONSECA, L. V. da. O estado, o terceiro setor e o mercado: uma tríade complexa. In: CONGRESSO BRASILEIRO DE CONTABILIDADE, 16., 2000, Goiás. Anais... Goiás, 2000.

GIL, A. C. Métodos e técnicas de pesquisa social. 5. ed. São Paulo: Atlas, 1999.

HENDRIKSEN, E. S.; VAN BREDA, M. Teoria da contabilidade. São Paulo: Atlas, 1999.

GRZYBOVSKIIL, D.; HAHN, T. Educação fiscal: premissa para melhor percepção da questão tributária. Revista de Administração Pública (RAP), Rio de Janeiro, v. 40, n. 5, set./out. 2006, pp. 841-864.

IUDÍCIBUS, Sérgio de. Teoria. Contabilidade. 6.ed. São Paulo: Atlas, 2000.

IUDÍCIBUS, S.; LOPES, A. S. B. Teoria avançada da contabilidade. São Paulo: Atlas, 2004.

KOHAMA, H. Contabilidade pública: teoria e prática. 9. ed. São Paulo:Atlas, 2003.

. Balanços públicos: Tteoria e prática. 2. ed. São Paulo:Atlas, 2009.

MARTINS, G. A.; THEÓPHILO, C. R. Metodologia da investigação científica para ciências sociais aplicadas. São Paulo: Atlas, 2007.

MATIAS-PEREIRA, J. Manual de gestão pública contemporânea. 2. ed. São Paulo: Atlas, 2009a.

REUNIR - Revista de Administração, Contabilidade e Sustentabilidade ISSN: 2237-3667 - Vol.3, no 4, Set./Dez., p. 39-61, 2013. 
BORGES, E. F.; et al. Educação Fiscal, Terceiro Setor e Funções de Governo... . Finanças públicas. A política orçamentária no Brasil. 4. ed. São Paulo: Atlas, 2009b.

MAZZON, J. A. Formulação de um modelo de avaliação e comparação de modelos em Marketing. 1978. 100f. Dissertação (Mestrado em Administração) - Departamento de Administração da Faculdade de Economia, Administração e Contabilidade da Universidade de São Paulo, São Paulo, 1978.

NEVES, J. L. Pesquisa qualitativa: características, usos e possibilidades. Caderno de Pesquisa em Administração. v. 1, n. 3. São Paulo, 1996. Disponível em: <www.ead.fea.usp.cad-pesq/arquivos/C03-art06.pdf>. Acesso em: 04 abr. 2010.

NIYAMA, J. K.; SILVA, C. A. T. Teoria da contabilidade. São Paulo: Atlas, 2008.

NÚCLEO DE INDICADORES CONTÁBEIS BRASILEIROS. Indicadores Contábeis Brasileiros - ICB'S. Disponível em: <http://www.nicb.ufsc.br> Acesso: 30 mar. 2010.

OLAK, P. A. Bases para a eficácia na aplicação do contrato de gestão nas organizações sociais brasileiras. 2000. 214f. Tese (Doutorado em Controladoria e Contabilidade) - Faculdade de Economia, Administração e Contabilidade da Universidade de São Paulo, São Paulo, 2000.

OLAK, P. A.; NASCIMENTO, D. T. do. Contabilidade para entidades sem fins lucrativos: terceiro setor. São Paulo: Atlas, 2006.

PAULO, E. Manipulação das informações contábeis: uma análise teórica e empírica sobre os modelos operacionais de detecção de gerenciamento de resultados. 2005. 195f. Tese (Doutorado em Ciências Contábeis) - Programa de Pós-Graduação em Ciências Contábeis, Departamento de Contabilidade e Atuária, Faculdade de Economia, Administração e Contabilidade da Universidade de São Paulo, São Paulo, 2005.

PERTUZUTTI, E; MERLO, R. A. O programa de educação fiscal do Estado de Santa Catarina: Uma reflexão sobre o papel do contador. Revista Universo contábil. v. 1, n. 3, set./dez., 2005, p. 48-62.

REUNIR - Revista de Administração, Contabilidade e Sustentabilidade ISSN: 2237-3667 - Vol.3, no 4, Set./Dez., p. 39-61, 2013. 
BORGES, E. F.; et al. Educação Fiscal, Terceiro Setor e Funções de Governo...

PRADO, O.; LOUREIRO, M. R. G. Governo eletrônico, transparência e democracia: a publicação das contas públicas das capitais brasileiras. In: CONGRESSO BRASILEIRO DE CONTABILIDADE, 17, 2004, Santos. Anais... Santos, 2004.

PROGRAMA CIDADÃO NOTA 10. GOVERNO DP ESATDO DO RN. Disponível em:

$<$ http://www.rn.gov.br/contentproducao/aplicacao/govrn/acoes_de_governo/enviado s/acoes_detalhe.asp?nCodigo=16>. Acesso em: 02 abr. 2010.

SALAMON, L. M. A emergência do terceiro setor: uma revolução associativa global. Revista de Administração, São Paulo: USP, v. 33, n. 1, jan./mar., 1998, p. 5-11.

SCARPIN, J E. Estudo dos fatores condicionantes do índice de desenvolvimento humano nos municípios do Estado do Paraná: instrumento de controladoria para a tomada de decisões na gestão governamental. 2006. 393f. Tese (Doutorado em Controladoria e Contabilidade) Programa de Pós-Graduação em Ciências Contábeis, Departamento de Ciências Contábeis, Faculdade de Economia, Administração e Contabilidade da Universidade de São Paulo, São Paulo, 2006.

SLOMSKI, V. Manual de contabilidade pública: um enfoque na contabilidade municipal. 2. ed. São Paulo: Atlas, 2008.

STEVENSON, W. J. Estatística aplicada à administração. São Paulo: Harper \& Row do Brasil, 1981.

TACHIZAWA, T. Organizações não governamentais e Terceiro Setor: criação de ONGs e estratégias de atuação. 2. ed. São Paulo: Atlas, 2004.

TELLES, R. A efetividade da matriz de amarração de Mazzon nas pesquisas em Administração. Revista de Administração. São Paulo, v. 36, n. 4, out./dez., 2001, pp. 64-72. 